\title{
Tıpta Uzmanlık Eğitimi Alan Araştırma Görevlilerinin Havayolu Yönetimi Deneyimlerine Anesteziyoloji ve Reanimasyon Staj ve Rotasyonunun Katkısının Değerlendirilmesi
}

\section{Evaluation of the Contribution of Anesthesiology and Reanimation Job Rotation and Internship to the Residents' Experiences of Airway Management in Medical and Surgical Specialties}

\author{
Gülçin Hacıbeyoğlu (Orcid: 0000000294383414$)$ \\ Şule Arican (Orcid: 0000000286341150$)$ \\ Sema Tuncer Uzun (Orcid: 0000000262051706$)$ \\ Aybars Tavlan (Orcid: 0000000260640179$)$ \\ Necmettin Erbakan Üniversitesi, Meram Tıp Fakültesi, Anesteziyoloji ve Reanimasyon Anabilim Dalı, Konya, Türkiye \\ Sorumlu Yazar: Gülçin Hacıbeyoğlu
}

Anahtar Sözcükler:

Anesteziyoloji, tıbbi uzmanlık, eğitim, havayolu yönetimi

Keywords:

Anesthesiology, medical specialty, training, airway management

Gönderilme Tarihi

Submitted:12.05.2019

Kabul Tarihi

Accepted: 24.09.2019

\section{ÖZET:}

Amaç: Bu çalışma; tıpta uzmanlık eğitimi alan klinik branş araştırma görevlilerinin havayolu yönetimi ile ilgili deneyimlerini ve bu deneyime Anesteziyoloji ve Reanimasyon staj ve rotasyonunun katkısını belirlemeyi amaçlamaktadır.

Gereç ve Yöntem: Necmettin Erbakan Üniversitesi Meram Tip Fakültesi'nde, dahili ve cerrahi branşlarda uzmanlık eğitimi alan araştırma görevlileri üzerinde, havayolu yönetiminde teorik bilgi ile pratik deneyimlerini ve Anesteziyoloji ve Reanimasyon staj ve rotasyonunun bu deneyime katkısını ölçmek için 26 sorudan oluşan bir anket çalışması yapıldı. Anket sorularına verilen cevapların değerlendirmesinde tanımlayıcı istatistiki analizler kullanıldı.

Bulgular: Anket sonuçlarının cevapları değerlendirildiğinde; katılımcıların \%95,7'si havayolu gereçleri ve kullanımları ile ilgili eğitim aldıklarını, \%82,2'si bu eğitimi ilk olarak anestezi stajında aldıklarını, \%56,7'si ilk endotrakeal entübasyonu anestezi

Künye: Hacıbeyoğlu G, Arıcan Ş, Tuncer Uzun S, Tavlan A. Tipta Uzmanlık Eğitimi Alan Araştırma Görevlilerinin Havayolu Yönetimi Deneyimlerine Anesteziyoloji ve Reanimasyon Staj ve Rotasyonunun Katkısının Değerlendirilmesi. Tıp Eğitimi Dünyast. 2019;18(56):30-44 
stajında yaptığını, \%59,2'si airwayi ilk anestezi stajında kullandığını, \%34,2'si daha önce laringeal mask airway kullandığını, \%50'si laringeal mask airwayi ilk olarak anestezi stajında kullandığını belirtmiştir. Anesteziyoloji ve Reanimasyon rotasyonu yapmayan katılımciların \%61'i bu durumu uzmanlık eğitimleri açısından bir eksiklik olarak görmektedir. Katılımcıların \%70'i rotasyon sonrası kendilerini havayolu yönetimi açısından yeterli bulmaktadır. Kendini yeterli bulmayan katılımcılar ise eğitimdeki pratik uygulamaların artırılması gerektiğini ve sürenin az olduğunu belirtmişlerdir.

Sonuç: Anket sonuçlarımıza göre havayolu yönetimi eğitiminde Anesteziyoloji ve Reanimasyon stajı önemli bir yer tutmaktadır. Farklı branşlarda uzmanlık eğitimi alan hekimlerin Anesteziyoloji ve Reanimasyon rotasyonunun gerekliliğini belirtmeleri rotasyon programlarının yeniden gözden geçirilmesini gündeme getirebilir. Verilen eğitimlerin özellikle pratik bölümündeki eksiklikler gözardı edilmemelidir. Çalışmamızın havayolu yönetimi eğitimi ile ilgili düzenlemelere katk1 sağlayacağı kanaatindeyiz.

\section{ABSTRACT:}

Background: The aim of this study was to assess the airway management experiences of residents and to determine the contributions of job rotations in Anesthesiology-Reanimation.

Material and Method: A 26-question survey was conducted at Necmettin Erbakan University Meram Faculty of Medicine, on the medicine and surgery residents to evaluate their theoretical knowledge and practical experiences in airway management and to determine the contribution of job rotations in Anesthesiology-Reanimation.
The responses to the questionnaire were evaluated with descriptive statistical analyses.

Results: The results revealed that $95.7 \%$ of the participants were trained about the airway management instruments; $82.2 \%$ took this training during their internship period in anesthesia; $56.7 \%$ performed endotracheal intubation for the first time during their anesthesia internship; 59.2\% used airways for the first time in their anesthesia internship; $34.2 \%$ had previously used laryngeal mask airways; and 50\% used laryngeal mask airways for the first time during their anesthesia internship. Of the participants who did not have a job rotation in Anesthesiology-Reanimation, 61\% perceived it as the incompleteness of the specialty training. Of the participants, $70 \%$ considered themselves competent for airway management after the job rotation. The participants, who considered themselves incompetent, reported that the duration of the training was short and that practical training should be promoted.

Conclusion: The results of our survey demonstrated that Anesthesiology-Reanimation internship is important in airway management training. The residents in different specialty areas have reported that a rotation in Anesthesiology and Reanimation is necessary, possibly raising the issue that a revision in the job rotation schedules is needed. Any incompleteness in practical training should not be overlooked. We believe that our study will contribute to regulations about airway management training.

\section{GíRİ̧̧}

Topluma nitelikli ve yeterli bir sağlık hizmeti sunulabilmesi için tıpta uzmanlık öğrencilerinin güncel bilgi birikimi ve yeterli donanımı kazanmaları önemlidir. Bu kazanımlar eğitim kurumlarında uzmanlık öğrencilerinin gözlem 
ve gönüllülüklerine bırakılmamalıdır (1). Bu nedenle anket çalışmaları ile verilen uzmanlık eğitiminin kanıta dayalı olarak değerlendirilmesi önem kazanmaktadır. Tıpta uzmanlık eğitimi geleneksel yöntemlerle çağdaş modellerin harmanlandığı bir eğitimdir. Uzmanlık eğitimi çerçevesinde eğitime yönelik kaynakların akılcı kullanımı ve verimliliğin artırılması için belli standartlara uyulması gerekmektedir. Eğitimi verecek farklı birimler portföylerini birlikte kullanarak eğitimin kapasitesini ve niteliğini artırabilirler (2). Tüm bilim dallarında olduğu gibi tıpta uzmanlık eğitiminde de güncellenen bilgiler ve değişen gereksinimler nedeniyle bazı yenilikler yapılması zorunlu hale gelmektedir. Özellikle devredilebilir profesyonel etkinlikler (EPA) 1şı̆̆ında verilen eğitimin düzenlenmesi ve yeterlik temelli uzmanlık eğitimi gün geçtikçe önem kazanmaktadır (3).

Tıpta Uzmanlık Kurulu'nun belirlediği eğitim standartlarına göre kurum, uzmanlık öğrencilerine bir aydan az olmamak üzere teorik ve pratik metodlarla acil müdahale uygulamalarının eğitimini vermekle yükümlüdür (4). Havayolu güvenliğinin sağlanması da pek çok klinik durumda hayat kurtaran acil bir müdahaledir. Dolayısıyla sadece anestezi uzmanlarının değil diğer branş hekimlerinin de bu konuda yeterli olmaları beklenir. Ancak günümüzde 21-23/06/2010 tarih ve 82 No'lu Tipta Uzmanlik Kurulu'nun gerekçesine ulaşılamayan kararında cerrahi tıp bilimlerinin büyük çoğunluğunda Anesteziyoloji ve Reanimasyon rotasyonu varken dahili tıp bilimlerinden sadece Acil Tıp ve Göğüs Hastalıkları uzmanlık eğitiminde rotasyon gerekli görülmüştür (5).

$\mathrm{Bu}$ çalışmada dahili ve cerrahi branş araştırma görevlilerinin havayolu yönetimi ile ilgili deneyimleri ve Anesteziyoloji ve Reanimasyon staj ve rotasyonunun bu deneyime katk1s1 değerlendirilmiştir. Çalışma sonuçlarının; tıp fakültelerindeki yeterlik temelli uzmanlık eğitimi programlarının düzenlenmesinde katk1 sağlayacağını öngörmekteyiz.

\section{Yöntemler:}

Çalışma yerel etik kurul onayı alınarak, tek merkezli olarak Necmettin Erbakan Üniversitesi Meram Tip Fakültesi'nde gerçekleştirildi. Çalışmanın evrenini tıpta uzmanlık eğitimi alan Anesteziyoloji ve Reanimasyon Anabilim Dalı dışındaki dahili ve cerrahi branş araştırma görevlileri oluşturdu. Tüm katılımcılara çalışmanın amacı anlatılarak dağıtılan anket formları tanitıld1. Katılımcilara anketin kesinlikle bir sınav olmadığı, katılımcılardan alınan kimlik bilgilerinin acıklanmayacağı, tüm verilerin bilimsel calışma için kullanılacağı açıklanarak onayları alındı. Çalışma gönüllülük prensibine göre yürütüldü. Anket formu çalışmanın amaç ve kapsamına uygun şekilde hazırlanan 26 sorudan oluşturuldu. Sorular uzmanların görüşü eşliğinde literatür ve uzmanlık eğitimi çekirdek/çerçeve programları dikkate alınarak hazırlandı. 14 soru kapalı uçlu, 6 soru çoktan seçmeli, 6 soru açık uçlu soruldu. Ankette katılımcıların demografik bilgileri, hangi anabilim dalında görevli oldukları, kaç yıldır meslekte oldukları, tıp eğitimlerinin başladığı günden bugüne havayolu yönetimi ile ilgili bilgi ve deneyimleri, anesteziyoloji ve reanimasyon rotasyonu yapıp yapmadıkları, yapmiyorlarsa bunu bir eksiklik olarak görüp görmedikleri (1-20.sorular) sorguland1. Anketin ikinci bölümünü anesteziyoloji ve reanimasyon rotasyonu yapan katılımcıların cevaplaması istendi. Bu bölümde (21-26.sorular) rotasyonun havayolu yönetimine katkısı belirlenmeye çalışıldı ve rotasyonla ilgili görülen eksikliklerin belirtilmesi istendi.

Tüm veriler için SPSS 23.0 programı 
kullanılarak deskriptif analiz (yüzde, ortalama \pm standart sapma) yapıldi.

\section{Bulgular:}

Çalışmanın yapıldığı süreçte asistanlığı devam eden 292 araştırma görevlisinden çalışmaya katılmayı kabul eden 192 araştırma görevlisine anket formu dağıtıldı. Çalışma evreninin \% 65,7'sine ulaşıldı. Tüm formlar geri alınarak verilerinde eksik olmayan 187 katılımcının formu istatistiksel olarak değerlendirmeye alındı. Katılımciların 106 (\% 56,7)'sı erkek, 81 (\% 43,3)'i kadın idi. Katılımcıların yaş ortalaması 27,83 $\pm 2,82$ idi. T1p fakültesinden mezun olduktan sonra geçen süre ortalama 41,12 $\pm 28,66$ ay (en az 4 ay- en fazla 168 ay) idi. Katılımcıların araştırma görevlisi olarak ortalama çalışma süreleri $20,91 \pm 16,76$ ay (en az 1 ay-en fazla 62 ay) idi. Dahili branşlarda çalışan araştırma görevlisi sayısı 105 (\% 56,1), cerrahi branşlarda çalışan araştırma görevlisi sayısı ise $82(\% 43,9)$ idi. Çalışmaya katılan hekimlerin görev yaptıkları anabilim dalları Tablo 1'de verilmiştir.

“Tıp eğitiminizin başladığı günden bugüne havayolu gereçleri ve kullanımları ile ilgili eğitim aldınız mı?" sorusuna katılımcıların $179(\% 95,7)$ 'u evet, $8(\% 4,3)$ 'i hayır cevabını vermiştir. $\mathrm{Bu}$ eğitimi ilk nerede aldıkları sorusuna verdikleri cevaplar Grafik 1'de belirtilmiştir. Bu soruda diğer şıkkını işaretleyen 12 katılımcının tamamı ilk havayolu eğitimini tıp fakültesinde öğrenci iken acil stajında aldıklarını belirtmişlerdir.

“Tıp eğitiminizin başladığı günden bugüne hiç endotrakeal entübasyon yaptınız mi?" sorusuna kat1lımcıların $166(\% 88,8)$ 's 1 evet, $21(\% 11,2)$ 'i hayır cevabını vermiştir. İlk endotrakeal entübasyonu nerede yaptıkları sorusuna verdikleri cevaplar Grafik 2'de belirtilmiştir. Bu soruda diğer şıkkını işaretleyen 15 katılımcıdan 10'u intörn iken acil rotasyonunda, 2'si intörn iken kardiyoloji rotasyonunda, 3'ü intörn iken dahiliye rotasyonunda ilk kez endotrakeal entübasyon yaptıklarını belirtmişlerdir.

"Airway nedir biliyor musunuz?" sorusuna katılımcıların \%100'ü evet cevabını vermiştir. “Tıp eğitiminizin başladığı günden bugüne hiç airway kullandınız mı?" sorusuna katılımcıların 162 (\%86.6)'si evet, 25 (\%13,4)'i hayır cevabını vermiştir. Katılımcıların airwayi ilk nerede kullandıkları sorusuna verdikleri cevaplar Grafik 3'de belirtilmiştir. Bu soruda diğer şıkkını işaretleyen 7 katılımcının 5'i intörn iken acil rotasyonunda, 1'i intörn iken kardiyoloji rotasyonunda, 1'i intörn iken göğüs hastalıkları rotasyonunda airwayi ilk kez kullandıklarını belirtmişlerdir.

"Laringeal mask airway (LMA) nedir biliyor musunuz?" sorusuna katılımciların 160 $(\% 85,6)$ '1 evet, 27(\%14,4)'si hayır cevabını vermiştir. "Tip eğitiminizin başladığı günden bugüne hiç LMA kullandınız mı?” sorusuna katılımcıların $64(\% 34,2)$ 'ü evet, 123(\%65,8)'ü hayır cevabını vermiştir. Katılımcıların LMA'yı ilk nerede kullandıkları sorusuna verdikleri cevaplar Grafik 4'de belirtilmiştir. Bu soruda diğer şıkkını işaretleyen 2 katılımcının 1 'i intörn iken acil rotasyonunda, 1'i intörn iken kardiyoloji rotasyonunda LMA'yı ilk kez kullandıklarını belirtmişlerdir.

"Mallampati siniflaması nedir biliyor musunuz?" sorusuna katılımciların 110 (\%58,8)'u evet, 77 (\%41,2)'si hayır cevabını vermiştir. "Mallampati sınıflamasını ne zaman öğrendiniz?" sorusuna katılımcıların verdiği cevaplar Grafik 5' de belirtilmiştir.

Katılımciların "Zor havayolu belirteci olarak bildiklerinizi işaretleyiniz." sorusuna verdikleri cevaplar Tablo 2'de verilmiştir.

"Uzmanlık eğitiminiz süresince Anesteziyoloji ve Reanimasyon rotasyonu yapiyor musunuz?" 
sorusuna katılımcıların $110(\% 58,8)$ 'u evet, 77 (\%41,2)'si hayır cevabını vermiştir. "Anesteziyoloji ve Reanimasyon rotasyonu yapmıyorsanız bu durumu uzmanlık eğitiminiz açısından bir eksiklik olarak görüyor musunuz?" sorusuna rotasyon yapmayan 77 katılımcinın 47 (\%61)'si evet, 30 (\%39)'u hayır cevabını vermiştir. Rotasyonunu tamamlamış olan 53 katılımcıya toplam kaç ay rotasyon yaptıkları sorulduğunda 36 (\%68)'s1 1 ay, 17 (\%32)'si 2 ay cevabını vermiştir. "Rotasyon sürelerinin havayolu yönetimini öğrenmek açısından yeterli olduğunu düşünüyor musunuz?" sorusuna katılımcıların 41 (\%77)'i evet, 12 (\%23)'si hayır cevabını vermiştir. Hayır cevabı veren katılımcıların tamamının 1 ay süre ile rotasyon yaptığ1 tespit edilmiştir. "Rotasyonun havayolu yönetimi ve entübasyonu öğrenmek açısından faydalı olduğuna inanıyor musunuz? sorusuna 53 katılımcinın 42 (\%80)'si evet, 11 (\%20 )'i hayır cevabı vermiştir. "Rotasyon sonrası kliniğinizde takip ettiğiniz hastalara havayolu yönetimi açısından yaklaşımınız değişti mi?" sorusuna 53 katılımcının 37 (\%70)'si evet, 16 (\%30)'sı hayır cevabı vermiştir. "Rotasyonda aldığınız eğitim sonrası kendinizi havayolu yönetimi açısından yeterli buluyor musunuz?" sorusuna 53 katılımcinın 37 (\%70)'si evet, 16 (\%30)'sı hayır cevabını vermiştir. Kendini yeterli bulmayan 16 katılımciya rotasyon ile ilgili eksikler sorulduğunda ise pratik uygulamaların artırılması gerektiği ve sürenin az olduğu cevaplarını vermişlerdir.

\section{Tartışma:}

Tıp eğitimi doğrudan insan hayatını ilgilendiren son derece ciddi donanım gerektiren uzun bir eğitim sürecidir. Her alanda tıp eğitiminin amacı evreleri boyunca yüksek kalitede sağlık hizmeti sunmaktır. $\mathrm{Bu}$ nedenle gelişen koşullar ve güncel bilgi ve becerilere göre tıp eğitimi sürekli izlenerek evrensel standartlar sağlanmalıdır. Mezuniyet sonrası tıp eğitimi, hekimlerin gözetim altında yetkinliklerini geliştirdikleri ve pratik eğitime özel önem veren lisansüstü tıp eğitimidir. 2015 yılında Dünya Tıp Eğitimi Federasyonu (WFME), lisansüstü tıp eğitiminde kaliteyi artırmak için küresel standartları revize etmiştir. Bazı ülkelerde oldukça gelişmiş öğrenme programları uygulanırken bazılarında ise sadece pratik eğitime dayalı daha geleneksel yöntemler uygulanmaktadır. Mezuniyet sonrası tıp eğitiminin çerçevesi çizilirken, mevcut temel tıp eğitiminin sonuçları dikkate alınarak teorik ve pratik bileşenlerin entegrasyonu sağlanmalıdır. Eğitim programlarının amaç ve hedefleri tanımlanırken uzman dernekleri ve Sağlık Bakanlığı'nın yaptıkları araştırmaların sonuçları mutlaka göz önünde bulundurulmalıdır (6). WFME standartlarında da düzenli değerlendirme ve geri bildirim yoluyla verilen eğitimin kalitesinin ölçülmesi tavsiye edilmektedir (7). Bu bağlamda tıpta uzmanlık eğitimi alan araştırma görevlilerinin yeterliliğini ve aynı zamanda verilen eğitimin kalitesi ve eğiticilerin de kalitesini ölçen çalışmaların sayıları artmaktadır (8-10). Avrupa'da da farklı ülkelerde tıp fakültelerinde verilen lisans ve lisansüstü eğitimlerin etkinliğini ölçmek için anket değerlendirmeleri yapılmaktadır (11). Biz de yapmış olduğumuz anket çalışmasıyla fakültemizde çalışan araştırma görevlilerinin temel tıp eğitiminde ve uzmanlık eğitiminde aldıkları havayolu yönetimi eğitimi ile ilgili geri bildirim almayı amaçladık.

Günümüz lisans ve lisansüstü tıp eğitiminde kabul gören yaklaşım yeterliğe dayalı tıp eğitimidir. Son yıllarda, yeterliğe dayalı tıp eğitiminin temel becerilere odaklanan yapısı nedeniyle profesyonel çalışma hayatının gereklerini karşılamadığı tartışılmaktadır (12). EPA kavramı; 2005 yılından itibaren tıp eğitimi 
alanında yer almaya başlamıştır. EPA; belirlenmiş olan bir yeterlik düzeyine ulaşmış olan öğrencinin doğrudan gözetim ve denetim altında olmadan yüklenmesi ve yürütmesi beklenen mesleksel etkinliklerdir (11). Lisansüstü eğitimdeki sorunlar yeterlik temelli eğitim ile EPA entegrasyonu sağlanarak çözülebilir (13). Ayrıca mezuniyet öncesi ve sonrası tıp eğitiminin entegrasyonuna yönelik çalışmalar da her iki dönemin programlarını geliştirerek eğitime olumlu katkı sağlayacaktır (14). Başarılı bir uzmanlık eğitimi için tıp fakültelerinde alınan temel eğitimin rolü unutulmamalıdır. Bizim çalışmamızda da havayolu yönetimi ile ilgili pratik ve teorik pek çok temel bilginin, katılımcıların büyük çoğunluğu tarafından tıp fakültesinde Anesteziyoloji ve Reanimasyon stajında öğrenildiği tespit edildi. Katılımcıların $\%$ 80'ninden fazlası havayolu gereçleri ve kullanımı ile ilgili eğitimi ilk kez Anesteziyoloji ve Reanimasyon stajında aldıklarını belirtmişlerdir. $\mathrm{Bu}$ oran tıp fakültelerinde havayolu yönetimi ile ilgili verilen eğitimin temelini Anesteziyoloji ve Reanimasyon stajının oluşturduğunu göstermektedir. Mallampati sınıflaması havayolunu değerlendiren ve zor havayolu belirteci olarak kullanılabilen bir sınıflamadir (15). Katılımciların yarısından fazlası sınıflamayı bildiğini belirtmiştir. $\mathrm{Bu}$ katılımcıların çok büyük bölümü sınıflamayı Anesteziyoloji ve Reanimasyon staj1 ve rotasyonunda öğrenmişlerdir. $\mathrm{Bu}$ yüksek oran tıp fakültelerinde havayolu ile ilgili verilen teorik eğitimin temelini Anesteziyoloji ve Reanimasyon staj1 ve rotasyonunun oluşturduğunu göstermektedir.

Eğitimin pratik ayağının sorgulandığı sorularda ise Anesteziyoloji ve Reanimasyon stajı ve rotasyonunun pratik eğitime de katkısının yüksek olduğu görülmektedir. Katılımcıların büyük bölümü endotrakeal entübasyon yaptıklarını belirtmişılerdir. Katılımcıların yarısından fazlası uygulamayı ilk olarak Anesteziyoloji ve Reanimasyon stajinda yaptıklarını belirtmişlerdir. \% $\quad 34,3$ 'ü ilk endotrakeal entübasyonu tıp fakültesinden mezun olduktan sonra yapmışlardır. \% 17,4'ü pratisyen hekim iken yani mesleki olarak ilk bireysel sorumluluk aldıkları dönemde bu uygulamayı yapmak zorunda kalmışlardır. $\mathrm{Bu}$ oranın endotrakeal entübasyon gibi tecrübe isteyen bir girişim için yüksek olduğunu ve beceri kazandırmayı hedefleyen yeterlik temelli eğitim açısından bir eksiklik olduğunu düşünüyoruz. Katılımcıların \%13,4'ü en basit havayolu gereçlerinden biri olan airwayi hiç kullanmadıklarını belirtmişılerdir. Airway kullananların büyük bölümü bu uygulamayı ilk olarak tıp fakültesinden mezun olmadan yaptıklarını belirtmişlerdir. 'LMA' y1 biliyor musunuz ?" sorusuna \% 85,6 gibi yüksek bir oranda evet cevabı verilmiştir. Ancak pratik uygulama sorgulandığında katılımcıların sadece \%34,2'si LMA' yı kullandıklarını belirtmişlerdir. Uygulama yapanların büyük bölümü bu uygulamayı Anesteziyoloji ve Reanimasyon stajı ve rotasyonunda yapmışlardır. \% 22'si ise yine ilk uygulamayı pratisyen hekim iken yapmak zorunda kalmıştır. LMA hayat kurtaran, uygulaması kolay ve endotrakeal entübasyon kadar tecrübe gerektirmeyen bir havayolu aracıdır (16). Bu nedenle pratik uygulama firsatlarının daha yüksek olması gerektiğini düşünüyoruz.

ASA (American Society of Anesthesiologists Amerika Anestezistler Birliği) zor havayolunu "deneyimli bir anestezistin yüz maskesi ile ventilasyonda ve/veya trakeal entübasyonda güçlükle karşılaştığı klinik durumdur" diye tanımlar (17). Horlama, obezite, gebelik, Obstrüktif Uyku Apne Sendromu (OSAS), k1sa-kaslı boyun, tiromental mesafenin k1sa 
olması, yüksek Mallampati skoru, büyük dil, ağız açıklığının kısıtlı olması, kifoskolyoz, Ankilozan Spondilit, Romatoid Artrit, Down Sendromu, baş-boyun deformiteleri zor havayolu belirteçleri olarak kabul edilirler (18). Bu belirteçlerin sorgulandığı soruda seçeneklerin büyük kısmında \% 50'nin üzerinde farkındalık olduğu tespit edildi. Ancak gebelik katılımcıların $\%$ 26,7'si, Down Sendromu katılımciların $\% 38$ 'i, Romatoid Artrit ise \%24,1'i tarafindan zor havayolu belirteci olarak işaretlenmiştir. Ankete katılan 19 kadın hastalıkları ve doğum asistanından sadece 7'si gebeliği zor havayolu belirteci olarak işaretlemiştir. 23 pediatri asistanının 5'i Down Sendromu'nu, 21 dahiliye asistanının 6's1 Romatoid Artrit'i zor havayolu belirteci olarak işaretlemiştir. $\mathrm{Bu}$ sayılar uzmanlık alanlarına spesifik hasta gruplarının havayolu özellikleri ile ilgili farkındalığın düşük olduğunu göstermektedir. Pediatri ve dahiliye gibi havayolu girişimi yapan ve yoğunbakımı olan anabilim dallarında uzmanlık eğitimi açısından anestezi rotasyonunun teorik ve pratik eğitime katkısı olacağını düşünüyoruz. Rotasyon yapan kadın-doğum anabilim dalı asistanlarının gebelik ile ilgili zor havayolu farkındalığındaki yetersizlikleri nedeniyle rotasyonda verilen eğitimin etkinliğinin yeniden irdelenmesi gerektiğini düşünüyoruz.

Havayolu açıklığının birkaç dakikadan daha uzun süre sağlanamaması hipoksik beyin hasarına ve/veya ölüme neden olacaktır $(19,20)$. $\mathrm{Bu}$ nedenle her hekimin havayolu yönetimi ile ilgili yeterli bilgi ve becerisinin olması gereklidir. Anesteziyoloji ve Reanimasyon dışındaki dahili ve cerrahi branş hekimlerine havayolu ile ilgili eğitim Anesteziyoloji ve Reanimasyon rotasyonu ile verilmektedir. Ankete katılan 77 araştırma görevlisi rotasyon yapmayan anabilim dallarından olup \%61'i bu durumu uzmanlık eğitimleri açısından bir eksiklik olarak görmektedirler. Benzer şekilde Kandemir ve arkadaşlarının anatomi rotasyonunun uzmanlık eğitimine entegrasyonu ile ilgili yaptıkları çalışmada ankete katılan hekimlerin büyük çoğunluğu rotasyonun gerekli olduğunu belirtmişlerdir (21). Havayolu eğitiminin yapı taşı olan Anesteziyoloji ve Reanimasyon rotasyonunun tıp fakültesinde verilen yeterlik temelli eğitimdeki aksamalar da göz önüne alındığında tüm klinik branşların uzmanlık eğitiminin bir parçası olması gerektiğini düşünüyoruz.

Anesteziyoloji ve Reanimasyon rotasyonunda eğitim verilen en temel alan havayolu yönetimidir (18). Havayolu yönetimi anestezi uygulamasının köşe taşlarından biri olarak kabul edilmiştir. Alternatif eğitim yöntemleri ve eğitimin yapılandırılmasına yönelik çabalara rağmen, havayolu yönetimi ile ilgili temel tekniklerin kullanımı konusunda yeterli deneyime sahip olabilmek halen oldukça zor görünmektedir (18). Bunun en önemli nedenlerinden biri ameliyathanedeki kısa süreli eğitimler ve dolayısıyla az sayıda vaka görülmesidir. Diğer önemli bir neden anestezi uygulamasındaki mevcut değişikliklerdir. Bölgesel anestezi teknikleri ve supraglottik havayolu araçlarının giderek artan kullanımı maske ventilasyonu ve endotrakeal entübasyon pratiğinin azalmasına neden olmaktadır $(22,23)$. Bu eğitim esnasında rotasyonerlerin yeterli sayıda zorlu havayolu vakası görebilmeleri gereklidir (24). Verilen eğitimin geri bildirimine yönelik ise çok az sayıda çalışma mevcuttur $(25,26)$. Yapılan ankette rotasyonunu tamamlayan araştırma görevlilerinin büyük bölümü rotasyonun havayolu yönetimi ve entübasyonu öğrenmek açısından faydalı olduğunu belirtmişlerdir. \% 70'i klinikte takip ettikleri hastalara havayolu yönetimi açısından yaklaşımlarının değiştiğini belirtmişlerdir. Katılımcılar yine aynı oranda 
rotasyon sonrası kendilerini havayolu yönetimi açısından yeterli bulduklarını belirtmişlerdir. Benzer şekilde Denizci'nin yaptığı çalışmada da rotasyonerlerin $\% 78,3$ 'ü havayolunun sağlanması ve farklı gereçlerin kullanımı konusunda kendilerini yeterli görmektedir (26). $\mathrm{Bu}$ durum Anesteziyoloji ve Reanimasyon rotasyonunun ve havayolu eğitiminin klinik branşlardaki önemini vurgulamaktadır.

Yeterlik temelli uzmanlık eğitimi; ağırlıklı olarak gerçek çalışma ortamlarında yürütülen, mesleki performans için gerekli temel bilgi ve beceriyi kazandıran eğitim programlarıdır. Esas amaç beceride yeterlilik kazandırmaktır. Başarılı bir uzmanlık eğitimi için öğrencinin rotasyonlarda ne kadar zaman geçirdiğinden çok hedeflenen yeterlik düzeyine ulaşıp ulaşmadığına odaklanılmalıdır (14). Aynı eğitim kurumunda eğitim alsalar dahi uzmanlık öğrencilerinin gelişimleri birbirinden farklı olacaktır. Zamanı öncelikleyen programların etkinliği düşük olacak ve yetersizlik duygusuna sebep olacaktır. Belirlenen yeterlik düzeylerine ulaşana kadar esnetilebilen sürelerle eğitimi sürdürmek daha doğru olacaktır. Anesteziyoloji ve Reanimasyon rotasyonu zorunluluğu Tipta Uzmanlık Kurulu tarafindan Acil Tip, Beyin Cerrahisi, Çocuk Cerrahisi, Göğüs Cerrahisi, Göğüs Hastalıkları, Göz, Kadın-Doğum, KulakBurun-Boğaz, Plastik Cerrahi ve Üroloji için 1 ay, Genel Cerrahi, Kalp-Damar Cerrahisi ve Ortopedi için 2 ay olarak belirlenmiştir (27). Avrupa Birliği standartları kapsamında Sağlık Bakanlığ1 tarafindan hazırlanan dokümanda ise süre belirtilmeksizin Genel Cerrahi, KadınDoğum ve Ortopedi için Anesteziyoloji ve Reanimasyon rotasyonu önerilirken diğer uzmanlık dalları için özel bir vurgu yapılmamıştır (28). Çiçek ve arkadaşlarının yaptığı çalışmada temel bilimler, tıbbi farmakoloji ve tıbbi patoloji alanında uzmanlık eğitimi alan 74 araştırma görevlisinden aldıkları uzmanlık eğitimini değerlendirmeleri istenmiş ve "Rotasyonların alan ve süreleri yeterli mi?" sorusuna sadece $\%$ 48,1 oranında "yeterli" yanıtı alınmıştır (29). Bizim çalışmamızda farklı olarak rotasyon süreleri hekimler tarafindan yeterli bulunmuştur. Ancak rotasyon sonrasi kendilerini yetersiz gören hekimlerin tamamı rotasyon sürelerinin yetersizliğini belirtmişlerdir. Başarılı entübasyon yapabilmek için gerekli entübasyon denemesi sayısı tartışmalı olmakla beraber Filho 35'in üzerinde entübasyon yapıldığında yeterlilikten söz edilebileceğini belirtmiştir (30,31). Yapılan çalışmalarla entübasyondaki başarı oranlarının eğitim süreleri ile doğru orantılı olarak arttığ1 tespit edilmiştir (30,32). Çalışmamızda 53 katılımcinın 12'si $(\% 22,6)$ rotasyon süresinin havayolu yönetimini öğrenmek açısından yetersiz olduğunu belirtmiştir. Bu katılımcıların tamamının 1 ay süre ile rotasyon yaptığ 1 tespit edilmiştir. Rotasyon sonrası kendilerini havayolu yönetimi açısından yetersiz bulan 16 kat1lımc1 bunun sebebini rotasyon süresinin kısalığı ve pratik uygulamaların azlığı olarak belirtmiş̧tir. Havayolu eğitimi açısından uygulamada olan rotasyon sürelerinde yeterlik temelli eğitim hedeflerine ulaşılamadığını bu nedenle rotasyonlarda verilen eğitim programlarının yeniden gözden geçirilmesi gerektiğini düşünüyoruz.

Araştırma evreninin \%65,7'sine ulaşılmış olması, araştırma görevlilerinin branş dağılımlarının dengeli olmaması, anketin mesai saatleri içinde uygulanmış olması, tek merkezli çalışma olması, anketin yapıldığı dönemde rotasyon yapan anabilim dalı araştırma görevlilerinin tamamının rotasyonlarını tamamlamamış olması, rotasyon sürelerinin farklı olması araştırmamızın sınırlılıklarını oluşturmuştur. Ayrıca uzmanlık eğitimi çekirdek programlarındaki temel ve ileri yaşam desteği 
başlıklarına çalışmada yer verilmemiştir. $\mathrm{Bu}$ aşamadan sonra bu konular da benzer şekilde değerlendirilebilir. Bu nedenle çalışmamız, daha geniş kapsamlı çalışmalara yön verebilecek bir pilot çalışma olarak kabul edilebilir.

\section{Sonuç:}

Anket sonuçları ile tıp fakültelerinde verilen havayolu yönetimi eğitiminde Anesteziyoloji ve Reanimasyon stajının öneminin altı çizilmiştir. Uzmanlık eğitiminde Anesteziyoloji ve Reanimasyon rotasyonunun tüm branşlarda gerekli olduğu katılımcı hekimler tarafından vurgulanmıştır. Uzmanlık eğitiminde verilen havayolu yönetimi eğitiminin niteliğinin özellikle yeterlik temelli uzmanlık eğitimi kapsamında yeniden değerlendirilmesi gerekliliği tespit edilmiştir. Anestezi mesleki dernekleri başta olmak üzere eğitimden sorumlu tüm bileşenlerin biraraya gelerek geleneksel bir program yerine yeterlik temelli eğitim ve EPA entegrasyonu ile temel ve ileri yaşam desteği ve havayolu yönetimi eğitimini güncellenmeleri hekimlerin nitelikli eğitim alması açısından zorunlu görünmektedir. $\mathrm{Bu}$ bağlamda rotasyon sürelerinin uzatılmasından daha ziyade öğrencilerin yeterlik seviyesine ulaşmalarını sağlamak eğitimin ana hedefi olmalıdır. Elde edilen sonuçların Anesteziyoloji ve Reanimasyon staj ve rotasyon programlarının düzenlenmesinde yol gösterici olabileceği kanaatindeyiz.

Çıkar Çakışması: Yok

Finansal Destek: Yok

\section{KAYNAKÇA}

1. XXIII. Tıpta Uzmanlık Eğitimi Kurultayı TTB UDEK XV. Çalışma Grupları Sonuç / Kararlılık Bildirgesi, 09 Aralık 2017, Ankara.
2. Tipta Uzmanlık Kurulu Karar Tutanağ 1 Toplant1 Tarihi:05/11/2013, Toplant1 No:52, Karar No:399

https://dosyamerkez.saglik.gov.tr/ Eklenti/30928,tuk-karar-1231----421-5431069-1152-ve-1231-ile-degisik-399----webpdf. pdf?0 Ulaşım Tarihi:29/07/2019

3. Hauer KE, Kohlwes J, Cornett P, Hollander $\mathrm{H}$, ten Cate $\mathrm{O}$, Ranji SR, Soni K, Iobst W, O'Sullivan PS. Identifying entrustable professional activities in internal medicine training. J Grad Med Educ. 2013; 5(4):54-59.

4. Tıpta Uzmanlık Kurulu Eğitim Standartları Karar Tutanağı Toplantı Tarihi:12/10/2017, Toplant1 No:82, Karar No:1026 https:/tuk. saglik.gov.tr/TR,30423/tuk-egitim-standartlarihakkindakarar-no--1026.html Ulaşım Tarihi:29/07/2019

5. Tıpta Uzmanlık Kurulu Uzmanlık Eğitimi Rotasyonları Karar Tutanağı Toplantı Tarihi:21-23/06/2010, Toplant1 No:21, Karar No:82 https://tuk.saglik.gov.tr//TR,53124/ rotasyonlar.html Ulaşım Tarihi:29/07/2019

6.UTEAK Türkiye Mezuniyet Öncesi Tıp Eğitimi Ulusal Standartları 2009, Hacettepe Üniversitesi Hastaneleri Basımevi 2009, Ankara.

7.WFME Global Standards for Quality Improvement: Postgraduate Medical Education https://wfme.org/standards/pgme/ Ulaşım Tarihi:29/07/2019

8. Carraccio C, Englander R, Wolfsthal S, Martin C, Ferentz K. Educating the pediatrician of the 21st century: Defining and implementing a competency based system. Pediatrics 2004; 
113: $252-58$.

9. Copland HL, Hewson MG. Developing and testing an instrument to measure effectiveness of clinical teaching in an academic medical center. Acad Med 2000; 75: 161-6.

10. Afonso NM, Cardozo LJ, Mascarenhas OAJ, Aranha ANF, Shah C. Are anonymous evaluations a better assessment of faculty teaching performance? A comparative analysis of open and anonymous evaluation processes. Fam Med 2005; 37(1): 43-7.

11. ten Cate O, Chen HC, Hoff RG, Peters H, Bok H, \& Schaaf M. Curriculum development for the workplace using Entrustable Professional Activities (EPAs): AMEE Guide No. 99, Medical Teacher 2015; 37(11): 983-1002.

12. Swinga SR. Perspectives on competencybased medical education from the learning sciences, for the International CBME Collaborators. Medical Teacher 2010; 8: 663-8.

13. Knape JT, ten Cate TJ. Still too old, too smart and too expensive. Med Contact 2010; 65(13):582-85.

\section{Altıntaş L. Mezuniyet Sonrası Dönemde} Ölçme ve Değerlendirmenin Tasarımında Devredilebilir Mesleksel Etkinliklerin Önemi. Turkiye Klinikleri J Med Educ-Special Topics 2016;1(2).

15. Barash PG, Cullen BF, Stoelting RK, Cahalan MK, Stock MC, Ortega R, Sharar SR. Klinik Anestezi Temelleri, Havayolu Yönetimi. Kamil Toker (Çeviren) 1. Baskı, Wolters Kluwer, 2017, 373-92.
16. Monem A, Khan FA. Laryngeal mask airway insertion anaesthesia and insertion techniques. J Pak Med Assoc 2007;57(12): 607-11.

17. Practice guidelines for management of the difficult airway. An updated report by the American Society of Anesthesiologists task force on management of the difficult airway. Anesthesiology 2003;98(5): 1269-77.

18. Goldmann K, Ferson DZ. Education and training in airway management. Best Practice \& Research Clinical Anaesthesiology 2005; 19(4): 717-32.

19. Kovacheva VP, Brovman EY, Greenberg P, Song E, Palanisamy A, Urman RD. A Contemporary Analysis of Medicolegal Issues in Obstetric Anesthesia Between 2005 and 2015. Anesth Analg. 2019 Jun;128(6):1199-1207.

20. Honardar MR, Posner KL, Domino KB. Delayed Detection of Esophageal Intubation in Anesthesia Malpractice Claims: Brief Report of a Case Series. Anesth Analg. 2017 Dec;125(6):1948-1951.

21. Kandemir YB, Sindel M, Şenol Y. Tipta Farklı Uzmanlık Alanlarında Eğitim Süresince Anatomi Dersi Gereksinimi. Tıp Eğitimi Dünyas1, 2018; 52 (17): 50-5.

22. Hawkins JL, Gibbs CP, Orleans M, MartinSalvaj G, Beaty B. Obstetric anesthesia work force survey, 1981 versus 1992. Anesthesiology 1997; 87: 135-43.

23. Verghese C, Brimacombe JR. Survey of the laryngeal mask usage in 11.910 patients: safety and efficacy for conventional and nonconventional usage. Anesthesia and 
Analgesia 1996; 82: 129-33.

24.Tomlinson A. Effects of the EWTD on anaesthetic training in the UK. Anaesthesia 2005; 60 (1): 96-7.

25. Royal College of Anaesthetists. The CCT in Anaesthesia I General Principles. A Manual for Trainees and Trainers. London: Royal College of Anaesthetists; 2007. (http://www.wsoa. org.uk/files/1814/1468/8796/The_CCT_in_ anaesthesia.pdf) Ulaşım Tarihi:29/07/2019

26. Denizci Ezgi. Anesteziyoloji ve reanimasyon anabilim dalında rotasyoner olan sağlık personelinin erişkin hastalarda hava yolu gereçlerini tanıma ve kullanabilme, rotasyon sürecinde eğitim beklentilerinin karşılanabilme düzeylerinin değerlendirilmesi. Yayınlanmamış Uzmanlık Tezi, Hacettepe Üniversitesi Tip Fakültesi, Anesteziyoloji ve Reanimasyon AD, Tez no: 383149, Ankara, 2015.

27.Tipta Uzmanlı Kurulu Karar Tutanağ Toplant1 Tarihi:21-23/06/2010, Toplant1 No:21, Karar No:82

28.Giray A, Odabaş Y, Türkoğulları G, Ekmen A. T.C. Sağlık Bakanlığı Avrupa Birliği Koordinasyon Dairesi Başkanlığı- Avrupa Birliği'nde Tıp Uzmanlıkları Eğitimi ve Eğitim Merkezleri Denetim Şartları (Çalışma Dokümanı) Birinci Bask1, Kasım 2002, Ankara.

29. Çiçek C, Terzi C, Solak A, Arsu G, Batu J, Vatansever K, et al. Üniversite Hastanelerinde Temel Bilimler Alanında Uzmanlık Eğitimi: Tıpta Uzmanlık Öğrencisi Bakış Açısı İle. Mikrobiyol Bült. 2005; 39: 491-501.

30. Grissom TE, Sappenfield J, Galvagno SM
Jr, Cherry SV, Chang YC, Hu PF. Performance assessment in airway management training for nonanesthesiology trainees: an analysis of 4,282 airway procedures performed at a level-1 trauma center. Anesthesiology 2014; 120(1):185-95.

31. de Oliveira Filho GR. The construction of learning curves for basic skills in anesthetic procedures: An application for the cumulative sum method. Anesth Analg 2002; 95: 411- 6.

32. Sagarin MJ, Barton ED, Chng YM, Walls RM. National Emergency Airway Registry Investigators: Airway management by US and Canadian emergency medicine residents: A multicenter analysis of more than 6,000 endotracheal intubation attempts. Ann Emerg Med 2005; 46: 328-36. 
Tablo 1. Çalıșmaya katılan hekimlerin görev yerleri (\%)

\begin{tabular}{|c|c|c|}
\hline KLINIIKLER & SAYI & $\%$ \\
\hline Pediatri & 23 & 12,3 \\
\hline Acil & 22 & 11,8 \\
\hline Dahiliye & 21 & 11,2 \\
\hline Kadın-Doğum & 19 & 10,2 \\
\hline Genel Cerrahi & 14 & 7,5 \\
\hline Aile Hekimliği & 14 & 7,5 \\
\hline Ortopedi & 13 & 7,0 \\
\hline Kulak Burun Boğaz & 7 & 3,7 \\
\hline Plastik Cerrahi & 7 & 3,7 \\
\hline Psikiyatri & 6 & 3,2 \\
\hline Kalp Damar Cerrahisi & 6 & 3,2 \\
\hline Beyin Cerrahisi & 6 & 3,2 \\
\hline Göğüs Hastahkları & 5 & 2,7 \\
\hline Kardiyoloji & 5 & 2,7 \\
\hline Dermatoloji & 4 & 2,1 \\
\hline Göz & 4 & 2,1 \\
\hline Üroloji & 4 & 2,1 \\
\hline Íntaniye & 2 & 1,1 \\
\hline Nöroloji & 2 & 1,1 \\
\hline Göğüs Cerrahisi & 2 & 1,1 \\
\hline Çocuk Cerrahisi & 1 & 0,5 \\
\hline
\end{tabular}




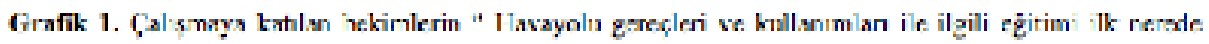
aldınz? ${ }^{*}$ sonusuna verdikleri cevapk.r.

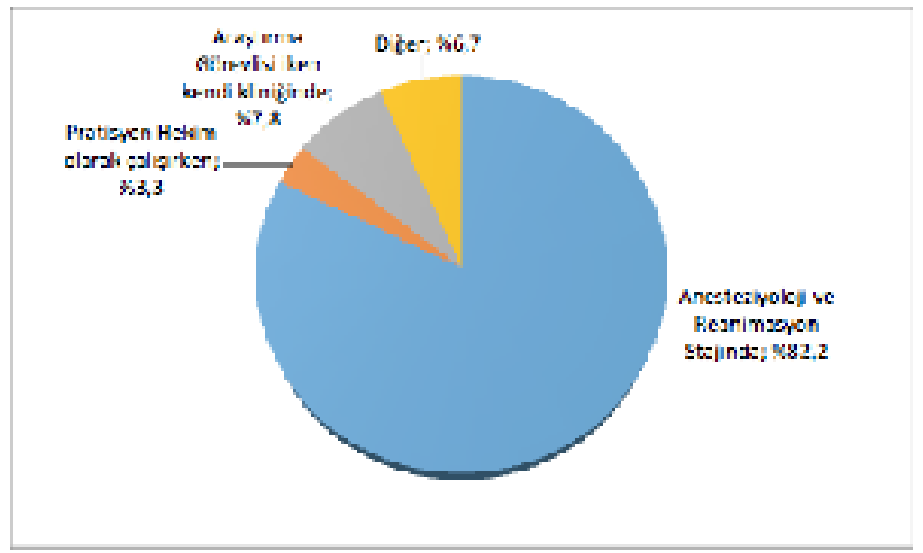

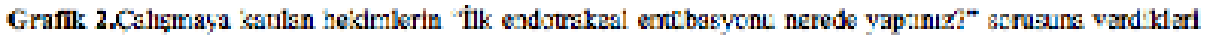
cevaplar.

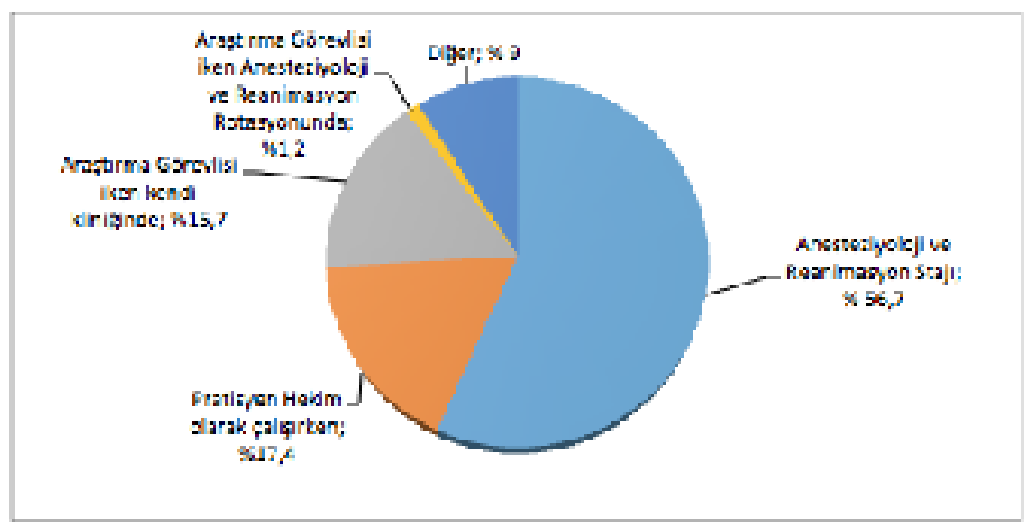


Grafik 3. Calıșmaya katılan hekimlerin "Airwayi ilk nerede kullandınız?" sorusuna verdikleri cevaplar.

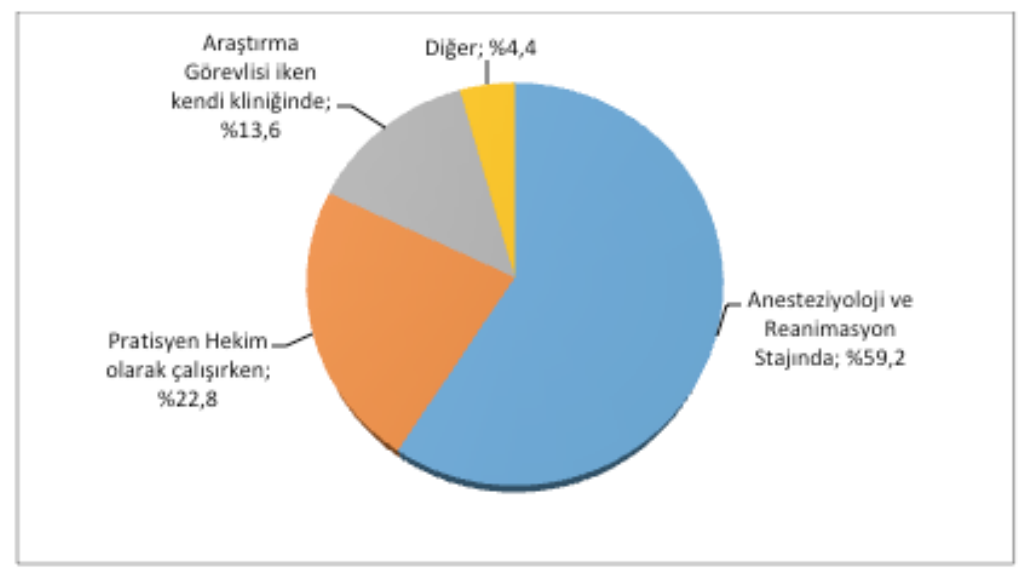

Grafik 4. Çalıșmaya katılan hekimlerin "LMA'yı ilk nerede kullandınız?" sorusuna verdikleri cevaplar.

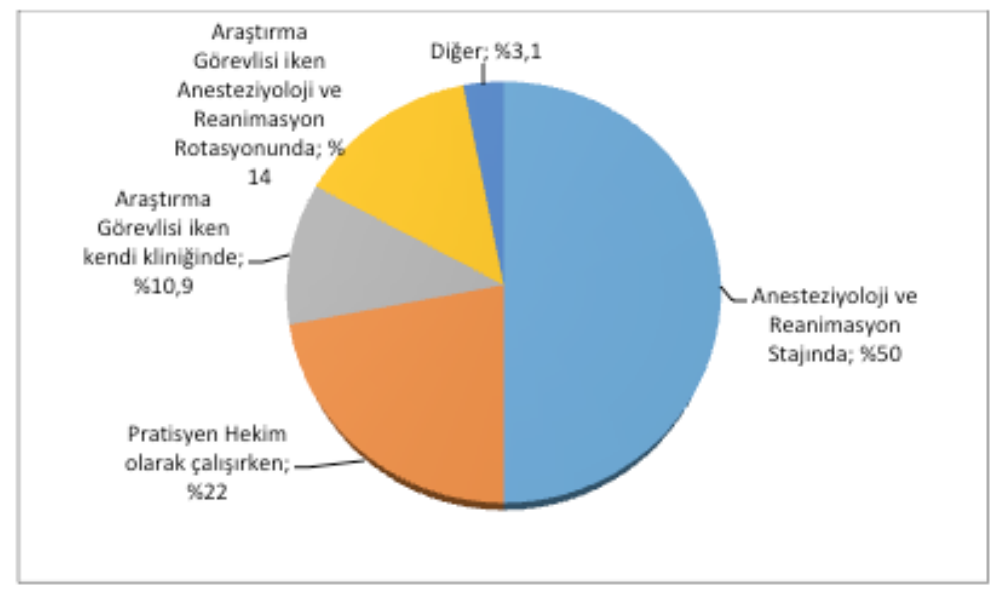


Grafik 5. Çalışmaya katılan hekimlerin “ Mallampati sınıflamasını ne zaman öğrendiniz?” sorusuna verdikleri cevaplar.

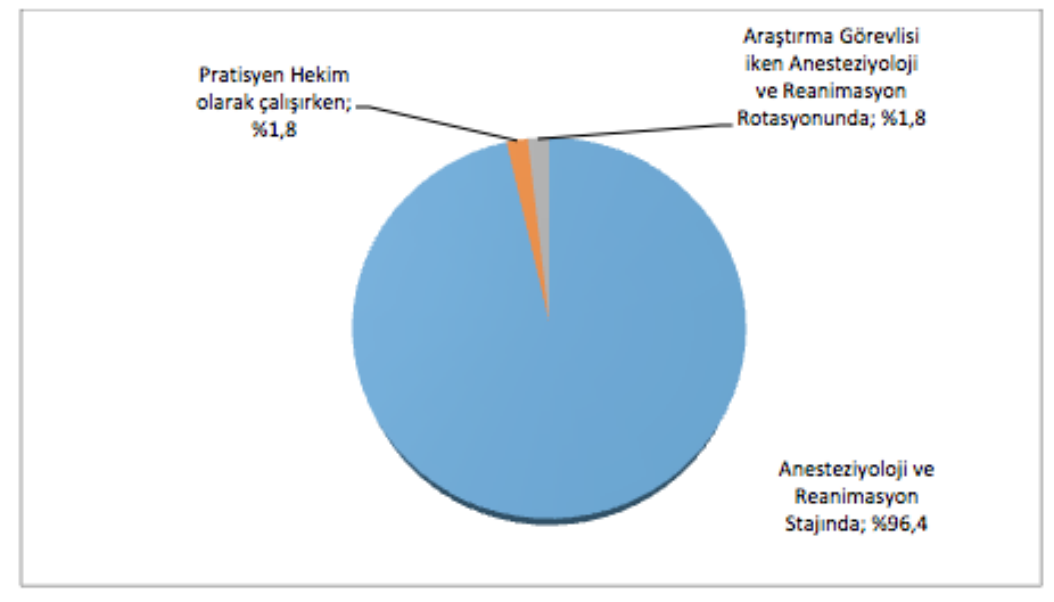

Tablo 2. Çalıșmaya katılan hekimlerin "Zor havayolu belirteci olarak bildiklerinizi ișaretleyiniz." cevaplarn (\%)

\begin{tabular}{|l|l|l|}
\hline ZOR HAVAYOLU BELIRTECI & SAYI & $\%$ \\
\hline Horlama Óküsü & 110 & 58,8 \\
\hline Obezite & 171 & 91,4 \\
\hline Gebelik & 50 & 26,7 \\
\hline Kısa-kash boyun & 177 & 94,7 \\
\hline OSAS & 129 & 69 \\
\hline Tïromental mesafenin kısa olması & 106 & 56,7 \\
\hline Yüksek Mallampati Skoru & 113 & 60,4 \\
\hline Büyük dil & 155 & 82,9 \\
\hline Ağız açıklı̆̆ının kısıth olması & 159 & 85 \\
\hline Kifoskolyoz & 99 & 52,9 \\
\hline Ankilozan Spondilit & 94 & 50,3 \\
\hline Romatoid artrit & 45 & 24,1 \\
\hline Down Sendromu & 71 & 38 \\
\hline Baş-boyun deformiteleri & 151 & 80,7 \\
\hline
\end{tabular}

OSAS: Obstrüktif Uyku Apne Sendromu 